\title{
The influence of body weight of patients with chronic plaque psoriasis on biological treatment response
}

\author{
Anna Kisielnicka ${ }^{1}$, Aneta Szczerkowska-Dobosz ${ }^{2}$, Roman J. Nowicki² \\ ${ }^{1}$ Student Dermatological Society of Medical University of Gdansk, Gdansk, Poland \\ 2Department of Dermatology, Venereology and Allergology, Medical University of Gdansk, Gdansk, Poland \\ Adv Dermatol Allergol 2020; XXXVII (2): 168-173 \\ DOI: https://doi.org/10.5114/ada.2020.94835
}

\begin{abstract}
Psoriasis is a chronic inflammatory disease of the skin. The new era of biological therapies initiated a shift in the definition of the disease therapeutic success, however, recent reports in the literature draw attention to the treatment-induced weight gain in psoriatic patients. Therefore, it is worth considering the body mass index influence on the biological treatment of chronic plaque psoriasis, seeing that it has manifold associations with the disease and may play an important role in clinical practice management.
\end{abstract}

Key words: psoriasis, biological treatment, body mass index.

\section{Introduction}

Psoriasis is a chronic inflammatory disease of the skin, characterised by formation of scaling plaques as a result of premature differentiation and hyperproliferation of keratinocytes. Chronic plaque psoriasis is the most common clinical manifestation of the disease reaching about $2.0 \%$ of global prevalence.

The aetiology is believed to be genetic autoimmune with tumour necrosis factor $\alpha$ (TNF- $\alpha$ ) and interleukins 17, 12 and 23 playing a key role in pathogenesis of the disease. Greater understanding of the molecular pathomechanism of psoriasis enabled a targeted treatment of modere to severe cases with biological therapy [1]. Manifold analyses of biologics confirmed their higher efficacy and lack of organ toxicity and severe adverse reactions in comparison to standard systemic treatments. The standard therapy in European clinical practice involves 4 biologics - adalimumab, infliximab, etanercept (TNF- $\alpha$ antagonists) and ustekinumab (IL-12/23 inhibitor). Recently, clinicians have received a new treatment option - secukinumab and ixekizumab (IL-17A inhibitors) - that are believed to provide the most effective therapy results to date. With the exception of infliximab, they are administered by fixed weight-independent doses, doubled only for patients of body weight above $100 \mathrm{~kg}$ receiving ustekinumab [2].
Furthermore, the new era of biological therapies initiated a shift in the definition of a therapeutic success from PASI75 to PASI90. A high clinical response to the treatment is yet hard to achieve and may depend on patients' baseline characteristics, such as start point severity score (PASI), psoriasis duration, biological naivety and body mass index (BMI). Additionally, it is believed that abnormal body weight is also an independent drug discontinuation factor [3].

Recent studies indicate that psoriatic patients undergoing biological therapy show a higher prevalence of obesity, diabetes and cardiovascular disease in comparison to those on standard systemic treatment [4]. The disease itself is associated with significant comorbidities (hypertension, diabetes mellitus, hyperlipidaemia, obesity and metabolic syndrome), which may lead to severe health consequences. Specifically, body weight above $\mathrm{BMI} 30 \mathrm{~kg} / \mathrm{m}^{2}$ is considered as both the result of and risk factor for the disease [5]. Since multiple aspects including patient's age, gender, ethnicity, smoking, alcohol consumption, age at diagnosis, duration and severity of psoriasis and baseline C-reactive protein levels do not seem to affect the biological therapy intervention, BMI appears to be an important factor modifying the therapy process [6]. Therefore, it is worth considering the BMI influence on the biological treatment of chronic plaque psoriasis, seeing that it has so many associations with

Address for correspondence: Aneta Szczerkowska-Dobosz MD, PhD, Department of Dermatology, Venereology and Allergology, Medical University of Gdansk, 7 Debinki St, 80-211 Gdansk, Poland, phone: +48 509093 699, e-mail: adobosz@gumed.edu.pl Received: 29.12.2018, accepted: 1.03.2019. 
the disease and may play an important role in clinical practice management.

\section{Psoriasis and obesity}

A strong correlation between psoriasis prevalence, its clinical severity and patients' body mass is well recognised. Multiple observations concluded that psoriatic patients have a strong tendency towards being overweight $\left(\mathrm{BMI}>25 \mathrm{~kg} / \mathrm{m}^{2}\right)$ or even obese $\left(\mathrm{BMI}>30 \mathrm{~kg} / \mathrm{m}^{2}\right)$ in contrast to the disease-free population. The analysis of the phenomenon on same-gender siblings demonstrated that it might result from a greater genetic predisposition of psoriatic patients to abnormal body mass [5, 7].

What is more, there are some indications in the literature suggesting an influence of obesity on the origin of the disease, especially late-onset psoriasis (after $40^{\text {th }}$ year of age), however they are inconclusive and need further investigation. Basing on a large population-based cohort Norwegian research, it is hypothesised that body weight above BMI $27-28 \mathrm{~kg} / \mathrm{m}^{2}$ is associated with $40 \%$ higher risk of psoriasis. Obese and overweight patients often suffer from more severe disease symptoms in the context of the skin lesions area and inflammation, which significantly deteriorates their quality of life $[8,9]$.

The co-existence of both disorders may have its origin in their similar molecular pathogenesis. Obesity is linked with a low-level systemic inflammation followed by deregulated production of adipokines, hormones and cytokines by adipose tissue. This process is mediated by activated macrophages and T-lymphocytes, which induce further pro-inflammatory cascade consisting of IL-1b, IL-6, IL-12 and TNF- $\alpha$ [9]. The expansion of main adipokines (adiponectin, leptin, visfatin and resistin) connected to weight gain correlates with their elevated levels among psoriatic patients. Macrophages play a key role in TNF- $\alpha$ production, which likewise in psoriasis, is highly expressed in patients' skin and triggers an immunological response. Moreover, TNF- $\alpha$ and its receptor levels seem to be connected with waist-to-hip ratio, body weight and BMI. Recently, significantly elevated levels of another pro-inflammatory peptide named psoriasin confirmed a strong association between psoriasis and obesity due to its positive correlation with PASI and BMI [10-13].

Predisposition to abnormal body mass has its substantial clinical consequences, namely greater risk of inverse psoriasis and severe disease symptoms [14]. Furthermore, the state of chronic inflammation may also have a negative long-term impact on the cardiovascular disease risk. The elevated levels of pro-angiogenic leptin and correlating C-reactive protein damage the endothelium and promote atherosclerosis [11]. The process clinically manifests itself as hypertension, myocardial infarction and angina pectoris and is especially prominent in patients with moderate to severe chronic plaque psoriasis.
According to the results of a large population-based cross-sectional study HUNT3, there is a strong association between psoriasis and the cardiovascular disease risk, thus all patients should be monitored to avoid potential deadly consequences [15].

\section{Influence of biological treatment on body mass}

Biological treatment became a new era of clinical therapeutic options and is widely used in various medical fields. Recent reports in the literature draw attention to the weight gain in rheumatology and gastroenterology wards' patients undergoing biological treatment. This observation especially refers to patients with spondyloarthritis and Leśniowski-Crohn disease receiving anti-TNF- $\alpha$ drugs $[16,17]$. Introduction of the following therapy method to chronic plaque psoriasis patients led to occurrence of parallel trends in their body mass changes. In a large-scale retrospective study Saraceno et al. observed a significant weight increase, notably the most prominent in patients receiving infliximab and etanercept [18]. Given the link between psoriasis and chronic systemic inflammation, metabolic syndrome or cardiovascular disease it is vital to take recent findings into consideration. Moreover, some authors put forward a suggestion to incorporate patients' BMI as an independent parameter for either clinical trial studies or an individual drug selection [6].

The observed phenomenon results from inhibition of TNF- $\alpha$ cytokine, and therefore, its function. Endogenous TNF- $\alpha$ plays a highly complex regulatory role in metabolic pathways. Primarily, it leads to muscle loss by promoting protein breakdown, lipolysis and supressing the release of anabolic hormones (insulin, IGF-1) and growth factors. Also, elevated levels of catabolic hormones (IGH-1) and serum leptin promote further weight decrease [19]. Recently, the following mechanism was used in treatment of cachexia in rheumatoid arthritis patients by anti-TNF- $\alpha$ drugs administration [16]. Hence, neutralisation of TNF- $\alpha$ results in greater abundance of fat-free mass and, to a lesser extent, in undesirable fat mass. The overall significant mass increase contributes to reduced therapy compliance and a greater cardiovascular incidence risk [20, 21].

On the other hand, another therapeutic option i.e. IL-12/23 inhibitor may also indirectly promote increase in fat-free mass by down-regulation of mediators promoting TNF- $\alpha$ release [19]. Reports of biological therapy inducing weight increase in psoriatic patients, who already have a predisposition to abnormal body weight, raise concerns and need to draw clinicians' attention to treatment consequences and benefits ratio.

\section{Anti-TNF- $\alpha$ therapy and body weight}

Anti-TNF- $\alpha$ drugs constitute the most popular therapeutic option in chronic plaque psoriasis biological treat- 
ment, and therefore, it seems that they play the major role in the drug-induced weight increase effect. However, due to fundamental differences in the dosage and pharmacodynamics it is vital to differentiate between their specific influences (Table 1).

In general, some patients undergoing etanercept therapy demonstrate significant continuous weight gain, which leads to shrinking efficacy of the response rate in heavier individuals. Therefore, in order to achieve a treatment success it might be beneficial to narrow the target patients' population to individuals weighing below 95 $-100 \mathrm{~kg}$ [5]. Saraceno et al. described etanercept-derived weight gain as irregular in contrast to adalimumab and infliximab, which contributed at first to a significant mass increase and eventually to a gradual decrease after $76^{\text {th }}$ therapy week. What is more, BMI index increase was more prominent in patients with baseline normal mass [18].
Numerous comparative research and sub-analyses of REVEAL, CHAMPION and BELIEVE studies came to a unanimous conclusion with regard to adalimumab showing a strong relation of limited drug efficacy and higher patients' BMI range [5]. Furthermore, Di Lernia's et al. retrospective observational study reports the highest treatment discontinuation rate of adalimumab closely related to obese individuals in comparison to other antiTNF- $\alpha$ agents [22]. It might seem that, along with etanercept, adalimumab is not the best therapeutic option for obese patients. On the contrary, recent observations of a 9-year retrospective study by Chiricozzi et al. suggest quite the opposite - psoriasis and psoriatic arthritis patients benefited from the fixed-dosed therapy irrespective of their body weight. The efficacy of the treatment was compared with normal-weight control group, thus

Table 1. Summary: the influence of biological treatment on body mass in chronic plaque psoriasis

\begin{tabular}{|c|c|c|c|}
\hline $\begin{array}{l}\text { Biological } \\
\text { therapy }\end{array}$ & $\begin{array}{l}\text { Body mass } \\
\text { influence }\end{array}$ & Commetary & Literature \\
\hline \multicolumn{4}{|l|}{ TNF- $\alpha$ inhibitors: } \\
\hline Infliximab & Weight gain & $\begin{array}{l}\text { Weight-dependent dosing } \\
\text { allows heavier individuals } \\
\text { to achieve efficient } \\
\text { therapy response }\end{array}$ & $\begin{array}{l}\text { 1. Puig L. (2011) Journal of the European Academy of Dermatology } \\
\text { and Venereology; literature review article } \\
\text { 2. Tan E, Baker C, Foley P. (2013) Australasian Journal of Dermatology; } \\
\text { retrospective observational study, } N=143 \text {, observational period: } \\
48 \text { weeks }\end{array}$ \\
\hline Adalimumab & Weight gain & $\begin{array}{l}\text { 9-years retrospective } \\
\text { study reported beneficial } \\
\text { response irrespective of } \\
\text { body weight. Adalimumab } \\
\text { influence in obese needs } \\
\text { further research }\end{array}$ & $\begin{array}{l}\text { 1. Puig L. (2011) Journal of the European Academy of Dermatology } \\
\text { and Venereology; literature review article } \\
\text { 2. Di Lernia V, Tasin L, Pellicano R, et al. (2012) Journal of } \\
\text { Dermatological Treatment; retrospective observational study, } \\
N=194 \text {, follow-up: } 2 \text { years } \\
\text { 3. Chiricozzi A, Zangrilli A, Bavetta M, et al. (2017) Journal of the } \\
\text { European Academy of Dermatology and Venereology; retrospective } \\
\text { observational study, } N=316 \text {, observational period: } 9 \text { years }\end{array}$ \\
\hline Etanercept & Weight gain & $\begin{array}{l}\text { The most prominent } \\
\text { weight gain. Might be } \\
\text { beneficial to narrow } \\
\text { treatment target to } \\
\text { individuals with normal } \\
\text { BMI }\end{array}$ & $\begin{array}{l}\text { 1. Puig L. (2011) Journal of the European Academy of Dermatology } \\
\text { and Venereology; literature review article } \\
\text { 2. Saraceno R, Schipani C, Mazzotta A, et al. (2008) Pharmacological } \\
\text { Research; retrospective observational study, } N=230 \text {, observational } \\
\text { period: } 48 \text { weeks }\end{array}$ \\
\hline \multicolumn{4}{|l|}{ IL-12/23 inhibitor: } \\
\hline Ustekinumab & No & $\begin{array}{l}\text { Diminishing clinical } \\
\text { response in patients } \\
\text { above } 100 \mathrm{~kg} \text {. Individual } \\
\text { weight adjustment might } \\
\text { improve compliance }\end{array}$ & $\begin{array}{l}\text { 1. Puig L. (2011) Journal of the European Academy of Dermatology } \\
\text { and Venereology; literature review article } \\
\text { 2. Yanaba K, Umezawa Y, Ito T, et al. (2014) Archives of Dermatological } \\
\text { Research; retrospective cohort study, } N=111 \text {, observational period: } \\
3 \text { years } \\
\text { 3. Gisondi P, Conti A, Galdo G. (2013) British Journal of Dermatology; } \\
\text { prospective cohort study, } N=162\end{array}$ \\
\hline \multicolumn{4}{|l|}{ IL-17A inhibitors: } \\
\hline Secukinumab & No & $\begin{array}{l}\text { Good alternative for } \\
\text { overweight and obese } \\
\text { patients' population }\end{array}$ & $\begin{array}{l}\text { 1. Tamakura S, Takahashi A, Inoue Y, et al. (2018) Journal of } \\
\text { Dermatology; retrospective observational study, } N=68 \text {, } \\
\text { observational period: } 7 \text { months }\end{array}$ \\
\hline Ixekizumab & No & $\begin{array}{l}\text { Good alternative for } \\
\text { overweight and obese } \\
\text { patients' population }\end{array}$ & $\begin{array}{l}\text { 1. Egebeg A, Wu J, Korman N, et al. (2018) Journal of the American } \\
\text { Academy of Dermatology; randomized controlled 3-trial study, } \\
N 1=1296, N 2=1224, N 3=1346\end{array}$ \\
\hline
\end{tabular}


authors encourage adalimumab practice in obese, elderly or even insufficiently responsive patients [23].

Furthermore, three large-scale randomized placebocontrolled clinical trials showed weight independent efficacy of infliximab in context of PASI75 response. Owing to its weight-dependent dosing scheme, the therapeutic success is more achievable for heavier individuals (above 95-100 kg), although a simultaneous body mass increase effect is still present (mean of 2-3 kg) [5, 20]. Infliximab weight increment continues along with elevating leptin and high-density lipoprotein (HDL) cholesterol levels, which contribute to cardiovascular psoriasis comorbidities [21]. According to Gisondi et al., comparative treatment response with no dominant BMI increase effect can be achieved with anti-IL-12/23 drug ustekinumab [17].

It seems that anti-TNF- $\alpha$ therapies are becoming less promising in overweight and obese patients, hence, it might be vital to adjust psoriasis therapy to patients' individual characteristics or replace it with less weightintervening treatment.

\section{Anti-IL-12/23, anti-IL-17A therapies and body weight}

In opposition to anti-TNF- $\alpha$ treatment, ustekinumab does not display significant trends in body mass changes. Moreover, it presents manifold advantageous clinical features that might overbalance anti-TNF- $\alpha$ drugs i.e. lack of direct anabolic influence, prolonged disease remission (compared to infliximab), higher overall drug survival (compared to adalimumab and etanercept) and more rapid onset of clinical response (compared to etanercept) [20, 24-26]. Although ustekinumab might be more suitable for obese patients, it is not deprived of some weight-dependent effects. Analysis of PHOENIX1 and PHOENIX2 second phase studies showed diminishing clinical response to ustekinumab in heavier patients [27, 28]. Also, Yanaba et al. described a considerable decrease in PASI90 and PASI100 response rates in overweight and obese population (BMI > $25 \mathrm{~kg} / \mathrm{m}^{2}$ ). It is suggested that individual weight adjustment of ustekinumab doses might provide clinicians with more satisfying therapy outcomes [29].

Due to recent introduction of IL-17A-inhibitors to clinical practice, their correlation with body mass needs thorough investigation. However, the initial reports suggest a neutral effect of secukinumab and ixekizumab on patients' body mass. Takamura et al. described in a 7-year retrospective study constant BMI levels among patients receiving secukinumab and ustekinumab along with a significant BMI increase among those treated with infliximab. Likewise, Egeberg et al. observed no weight gain in patients on 12 weeks' ixekizumab treatment [30, 31].

For this reason, anti-IL-12/23 or anti-IL-17A therapies may constitute a good alternative to anti-TNF- $\alpha$ treat- ment for overweight and obese patients, who do not fully accomplish therapy compliance.

\section{Consequences of weight increase in response to biological treatment}

Abnormal body mass is associated with a considerably negative response of all systemic chronic plaque psoriasis treatments, including biological treatment. With a continuous increase in overweight and obese patients' population, the problem may escalate quickly. Nowadays, patients weighting above $100 \mathrm{~kg}$ constitute about $25-30 \%$ of clinical trial subpopulations and present a less frequent optimal response to biological therapy than the control group [5]. Pharmacokinetic interactions of the substance in systemic metabolism account for the problem in great measure. The drug clearance is deregulated by abundant adipose tissue, which expands the drug distribution volume. Eventually, set clinical drug doses become insufficient and limit the chances of therapeutic success. The problem is especially prominent in biologics with fixed-dosed schemes (such as etanercept and adalimumab) with short biological half-lives and may force overweight and obese patients to pay greater therapy costs in order to achieve therapeutic goals [20, 22].

The major therapeutic dilemmas of such dependence are reduced systemic efficacy and inefficient clinical response. Umezawa et al. along with other authors suggest a significantly limited value of anti-TNF- $\alpha$ treatment in patients with increasing BMI score, which is reflected in lower PASI75 and PASI reduction response rates. A nationwide cohort Italian study by Naldi et al. comprising all systemic treatments (including TNF- $\alpha$ inhibitors) described a continuous decrease in PASI score improvement with greater BMI values. Moreover, obese patients had relevantly less frequent response to standard systemic therapy after $8^{\text {th }}$ and $16^{\text {th }}$ week of PSOCARE trial. Similar relationship was noted in Yanaba et al. study for ustekinumab where authors concluded that obesity promotes higher pro-inflammatory mediator levels, which exceed the biologic agent efficacy potential [24, 29, 32].

Furthermore, an unsatisfactory treatment response may lead to drug discontinuation along with other predisposing factors i.e. systemic infections, side effects or female sex. A prospective multicentre long-term BioCAPTURE registry emphasised the predicting role of higher BMI index in treatment termination among patients receiving etanercept and ustekinumab [25]. According to Di Lernia et al., obese patients under antiTNF- $\alpha$ treatment in general are predisposed to therapy discontinuation after 12 and 24 months. Body mass index is suggested to play an independent important role in therapy maintenance, and therefore, it may be considered as a clinical prognostic factor of the response [22, 32]. In the foreseeable future, we might employ genetic polymorphism biomarkers to predict one's treat- 
ment response and individually adjust patients' best therapeutic options [33].

On the other hand, some studies did not provide statistical evidence to support the correlation between BMI and reduced efficacy of biological therapy [23]. For this reason, further investigation is needed to determine the importance of BMI as a modifiable variable of the treatment response in context of an inefficient clinical response and therapy discontinuation.

\section{Weight reduction effect on biological treatment}

Abnormal body mass and weight gain carry manifold therapeutic disadvantages, hence encouraging psoriatic patients to undertake weight reduction interventions seems to be an important treatment element. Low-calorie diet, physical exercise and, in extreme cases, gastric bypass surgery cover three main pillars of pro-healthy actions to decrease pro-inflammatory cytokines levels, inhibit cellular proliferation and achieve improvement in treatment response and disease management [7, 29].

What is more, weight reduction seems to have the greatest efficacy impact on agents administered by fixed doses. Among them, Al-Mutairi et al. demonstrated in a randomized controlled trial the predominance of ustekinumab PASI score decrease during dietary intervention over other biologics, especially etanercept [16]. Numerous clinical observational studies point out to weight loss as an important therapy-modifying factor of mild to severe chronic plaque psoriasis. Therefore, BMI index reduction, as a derivative of weight loss, is thought to be a prognostic factor of superior biological treatment response among overweight and obese patients (mean BMI: $30.6 \mathrm{~kg} / \mathrm{m}^{2}$ ) [6].

Furthermore, weight reduction may play an important role in both prevention and disease control by ameliorating psoriasis severity, i.e. scaling and erythema [8]. Bardazzi et al. reported an outstanding improvement of patients' PASI score correlated with weight loss. In addition, they observed a therapeutic success reaching up to PASI75 and PASI90 biological therapy responses in obese previously non-responsive patients [14].

To conclude, weight loss might be the easiest and the most significant means to achieve efficient biological therapy response, which transforms to patients' greater quality of life and better doctor-patient communication in disease management.

\section{Practical implications}

Although every obese patient should be encouraged to body mass control, it seems that weight loss might significantly contribute to chronic plaque psoriasis therapy response improvement. In particular, it is vital to promote low-calorie diet and physical exercise before and during the psoriasis biological treatment. Dermatological and nutritional cooperation might greatly contribute to successful disease management by promoting Mediterranean diet, which is highly recommended for psoriatic patients [34].

In a long-term perspective weight loss in psoriatic patients is very desirable in terms of greater prevalence of potentially deadly comorbidities: metabolic syndrome, insulin resistance or cardiovascular disease. The Framingham Heart Study described a 21-45\% greater chance of metabolic syndrome development even with a slight weight increase of about $2.25 \mathrm{~kg}$ in psoriatic patients. For this reason, the authors of the research suggested a careful screening for cardiovascular incident risk factors among patients receiving anti-TNF- $\alpha$ therapy [20].

Furthermore, patients' BMI index can be considered as an independent stratification parameter during clinical trials and therapeutic drug selection. It seems that some anti-TNF- $\alpha$ group biologics might have a greater influence on weight increase, and therefore should be avoided in overweight and obese patients if possible. Recent reports suggest that anti-IL-12/23 and anti-IL17A therapies constitute a good alternative for such population. Moreover, BMI based biological therapy with weight-adjusted doses may contribute to greater treatment efficacy, which is considered equal to patients' better quality of life and satisfaction. On the other hand, the pharmacoeconomic implications of the dose adjustments may trigger necessary discussion about ethical issues.

It seems that in the biological treatment era clinicians are still in search for the best therapy. The latest introduction of biologics, ixekizumab and secukinumab, to clinical practice may allow further study investigation and give psoriatic patients a new hope for more satisfying therapy outcomes.

\section{Conflict of interest}

The authors declare no conflict of interest.

\section{References}

1. Krueger JG. Hiding under the skin: a welcome surprise in psoriasis. Nat Med 2012; 18: 1750-1.

2. Rønholt K, Iversen L. Old and new biological therapies for psoriasis. Int J Mol Sci 2017; 18: 2297.

3. Zweegers J, Roosenboom B, van de Kerkhof P, et al. Frequency and predictors of a high clinical response in patients with psoriasis on biological therapy in daily practice: results from the prospective, multicenter BioCAPTURE cohort. Br J Dermatol 2017; 176: 786-93.

4. Reich K, Mrowietz U, Radtke M, et al. Drug safety of systemic treatments for psoriasis: results from the German Psoriasis Registry PsoBest. Arch Dermatol Res 2015; 307: 875-83.

5. Puig L. Obesity and psoriasis: body weight and body mass index influence the response to biological treatment. J Eur Acad Dermatol Venereol 2011; 25: 1007-11. 
6. Edson-Heredia E, Sterling K, Alatorre C, et al. Heterogeneity of response to biologic treatment: perspective for psoriasis. J Investig Dermatol 2014; 134: 18-23.

7. Murray M, Bergstresser P, Adams-Huet B, et al. Relationship of psoriasis severity to obesity using same-gender siblings as controls for obesity. Clin Exp Dermatol 2009; 34: 140-4.

8. Johnston A, Arnadottir S, Gudjonsson J, et al. Obesity in psoriasis: leptin and resistin as mediators of cutaneous inflammation. Br J Dermatol 2008; 159: 342-50.

9. Danielsen K, Wilsgaard T, Olsen A, et al. Overweight and weight gain predict psoriasis development in a populationbased cohort. Acta Derm Venereol 2017; 97: 332-9.

10. Xue K, Liu H, Jian Q, et al. Leptin induces secretion of proinflammatory cytokines by human keratinocytes in vitro - a possible reason for increased severity of psoriasis in patients with a high body mass index. Exp Dermatol 2013; 22: 406-10.

11. Kaur S, Zilmer K, Leping V, et al. The levels of adiponectin and leptin and their relation to other markers of cardiovascular risk in patients with psoriasis. J Eur Acad Dermatol Venereol 2011; 25: 1328-33.

12. Naldi L, Chatenoud L, Linder D, et al. Cigarette smoking, body mass index, and stressful life events as risk factors for psoriasis: results from an Italian Case-Control Study. J Investig Dermatol 2005; 125: 61-7.

13. Salama R, Al-Shobaili H, Al Robaee A, et al. Psoriasin: a novel marker linked obesity with psoriasis. Dis Markers 2013; 34: 33-9.

14. Bardazzi F, Balestri R, Baldi E, et al. Correlation between BMI and PASI in patients affected by moderate to severe psoriasis undergoing biological therapy. Dermatol Ther 2010; 23 Suppl: S14-9.

15. Snekvik I, Nilsen T, Romundstad P. Psoriasis and cardiovascular disease risk factors: the HUNT study, Norway. J Eur Acad Dermatol Venereol 2018; 32: 776-82.

16. Al-Mutairi N, Nour T. The effect of weight reduction on treatment outcomes in obese patients with psoriasis on biologic therapy: a randomized controlled prospective trial. Exp Opin Biol Therapy 2014; 14: 749-56.

17. Gisondi P, Conti A, Galdo G. Ustekinumab does not increase body mass index in patients with chronic plaque psoriasis: a prospective cohort study. Br I Dermatol 2013; 168: 1124-7.

18. Saraceno R, Schipani C, Mazzotta A, et al. Effect of antitumor necrosis factor-alpha therapies on body mass index in patients with psoriasis. Pharmacol Res 2008; 57: 290-5.

19. Owczarczyk-Saczonek A, Placek W, Rybak-d'Obyrn J, et al. Influence of ustekinumab on body weight of patients with psoriasis: an initial report. Adv Dermatol Allergol 2014; 31: 29-31.

20. Tan E, Baker C, Foley P. Weight gain and tumour necrosis factor-alpha inhibitors in patients with psoriasis. Austral J Dermatol 2013; 54: 259-63.

21. Ehsani A, Mortazavi H, Balighi K, et al. Changes in body mass index and lipid profile in psoriatic patients after treatment with standard protocol of infliximab. Acta Med Iran 2016; 54: 570-5.

22. Di Lernia V, Tasin L, Pellicano R, et al. Impact of body mass index on retention rates of anti-TNF-alfa drugs in daily practice for psoriasis. J Dermatol Treat 2012; 23: 404-9.

23. Chiricozzi A, Zangrilli A, Bavetta M, et al. Real-life 9-year experience with adalimumab in psoriasis and psoriatic arthritis: results of a single-centre, retrospective study. J Eur Acad Dermatol Venereol 2017; 31: 304-11.
24. Umezawa Y, Saeki H, Nakagawa H. Some clinical factors affecting quality of the response to ustekinumab for psoriasis. J Dermatol 2014; 41: 690-6.

25. Zweegers J, van den Reek J, van de Kerkhof P, et al. Body mass index predicts discontinuation due to ineffectiveness and female sex predicts discontinuation due to sideeffects in patients with psoriasis treated with adalimumab, etanercept or ustekinumab in daily practice: a prospective, comparative, long-term drug-survival study from the BioCAPTURE registry. Br J Dermatol 2016; 175: 340-7.

26. Griffiths C, Strober B, van de Kerkhof P, et al. Comparison of ustekinumab and etanercept for moderate-to-severe psoriasis. N Engl J Med 2010; 362: 118-28.

27. Papp K, Kimball A, Wasfi Y, et al. Long term efficacy and safety of ustekinumab in patients with moderate to severe psoriasis through 5 years of follow-up: results from the PHOENIX 1 long-term extension. J Dermatol 2012; 39: 63-4.

28. Papp K, Langley R, Lebwohl M, et al. Efficacy and safety of ustekinumab, a human interleukin-12/23 monoclonal antibody, in patients with psoriasis: 52 -week results from a randomised, double-blind, placebo-controlled trial (PHOENIX 2). Lancet 2008; 371: 1675-84.

29. Yanaba K, Umezawa Y, Ito T, et al. Impact of obesity on the efficacy of ustekinumab in japanese patients with psoriasis: a retrospective cohort study of 111 patients. Arch Dermatol Res 2014; 306: 921-5.

30. Takamura S, Takahashi A, Inoue Y, et al. Effects of tumor necrosis factor-alpha, interleukin-23 and interleukin-17a inhibitors on bodyweight and body mass index in patients with psoriasis. J Dermatol 2018; 45: 1130-4.

31. Egeberg A, Wu J, Korman N, et al. Ixekizumab treatment shows a neutral impact on cardiovascular parameters in patients with moderate-to-severe plaque psoriasis: results from UNCOVER-1, UNCOVER-2, and UNCOVER-3. J Am Acad Dermatol 2018; 79: 104-9.e8.

32. Naldi L, Addis A, Chimenti S, et al. Impact of body mass index and obesity on clinical response to systemic treatment for psoriasis: evidence from the Psocare Project. Dermatology 2008; 217: 365-73

33. Woolf R, Smith C. How genetic variation affects patient response and outcome to therapy for psoriasis. Exp Rev Clin Immunol 2010; 6: 957-66.

34. Barrea L, Balato N, Di Somma C, et al. Nutrition and psoriasis: is there any association between the severity of the disease and adherence to the mediterranean diet? J Transl Med 2015; 13: 18. 